\section{FGF signaling inhibits chondrocyte proliferation and regulates bone development through the STAT-1 pathway}

\author{
Malika Sahni, ${ }^{1}$ Davide-Carlo Ambrosetti, ${ }^{1}$ \\ Alka Mansukhani, ${ }^{1}$ Rachel Gertner, ${ }^{2}$ \\ David Levy, ${ }^{2}$ and Claudio Basilico ${ }^{1,3}$ \\ Departments of ${ }^{1}$ Microbiology and ${ }^{2}$ Pathology, New York \\ University School of Medicine, New York, New York \\ 10016 USA
}

Several genetic forms of human dwarfism have been linked to activating mutations in FGF receptor 3, indicating that FGF signaling has a critical role in chondrocyte maturation and skeletal development. However, the mechanisms through which FGFs affect chondrocyte proliferation and differentiation remain poorly understood. We show here that activation of FGF signaling inhibits chondrocyte proliferation both in a rat chondrosarcoma (RCS) cell line and in primary murine chondrocytes. FGF treatment of RCS cells induces phosphorylation of STAT-1, its translocation to the nucleus, and an increase in the expression of the cell-cycle inhibitor p21WAF1/CIP1. We have used primary chondrocytes from STAT-1 knock-out mice to provide genetic evidence that STAT-1 function is required for the FGF mediated growth inhibition. Furthermore, FGF treatment of metatarsal rudiments from wild-type and STAT-1 ${ }^{-/-}$ murine embryos produces a drastic impairment of chondrocyte proliferation and bone development in wildtype, but not in STAT-1 ${ }^{-/-}$rudiments. We propose that STAT-1 mediated down regulation of chondrocyte proliferation by FGF signaling is an homeostatic mechanism which ensures harmonious bone development and morphogenesis.

Received March 17, 1999; revised version accepted April 13, 1999.

FGFs are a large family of fibroblast growth factors that signal through their binding to specific tyrosine kinase receptors (FGFRs), which also constitute a four-member gene family (Basilico and Moscatelli 1992). FGF signaling has a major role in a variety of developmental processes, and recent results have highlighted its role in bone morphogenesis (for review, see Goldfarb 1996). Long bone growth results from endochondral ossification, a strictly regulated process that requires proliferation and differentiation of chondrocytes. Based on the evidence linking genetic forms of human dwarfism such as achondropla-

[Key Words: FGF signaling; chondrocytic maturation; bone development STAT-1]

${ }^{3}$ Corresponding author.

E-MAIL basilc01@mcrcr.med.nyu.edu; FAX (212) 263-8714. sia $(\mathrm{ACH})$, thanatophoric dysplasia (TD), and hypochondroplasia to activating mutations in FGFR3, as well as from the study of FGF transgenic (Coffin et al. 1995) or FGFR3 knockout mice (Colvin et al. 1996; Deng et al. 1996), it has been suggested that FGFs act as negative regulators of bone growth (Goldfarb 1996; Webster and Donoghue 1997; Burke et al. 1998; Naski and Ornitz 1998). However, the downstream events through which FGFs influence the proliferation or differentiation of osteogenic chondrocytes remain to be elucidated. In most cell types FGFs have a proliferative effect (Basilico and Moscatelli 1992), and in vitro studies have shown that FGF treatment of primary chondrocytes leads to an increase in cell proliferation and an inhibition of their differentiation (Kato and Iwamoto 1990; Hill et al. 1991; Wroblewski and Edwall-Arvidsson 1995; Legeai-Mallet et al. 1998), a finding that appears to be at variance with the evidence from human genetics. We therefore studied the biological response and the signal transduction pathways activated by FGF treatment of primary murine chondrocytes, as well as chondrocytic cell lines.

\section{Results and Discussion}

We used RCS cells, a rat chondrosarcoma cell line that exhibits most of the properties of proliferating chondrocytes. Among FGFRs these cells express exclusively FGFR3 as well as other chondrocyte markers, such as collagen II (not shown). We treated RCS cells with FGF1, a high affinity ligand for all known FGFR isoforms (Ornitz et al. 1996). Stimulation by FGF1 induces autophosphorylation of endogenous FGFR3 within $30 \mathrm{sec}$ (Fig. 1a) and leads to the phosphorylation of downstream molecules such as MAPK (Fig. 1c) and Shp-2 (not shown), which have been reported to be activated in other cell types upon FGF stimulation (Saxton et al. 1997). Surprisingly, FGF1 treatment did not stimulate proliferation of these cells but resulted in a drastic inhibition of growth, reflected in the frequency of DNA-synthesizing cells observed in the cultures (Fig. 1b). DNA synthesis inhibition was rapid and reached its maximum $\sim 1$ day after treatment. No evidence of increased apoptosis was observed (not shown).

It has been reported that a mutated form of FGFR3, carrying the strongly activating TDII mutation, can induce STAT-1 phosphorylation and DNA binding in transient transfection assays in 293 cells (Su et al. 1997). STAT-1, originally identified as a signal transducing molecule in the IFN pathway, is activated by tyrosine phosphorylation and translocated to the nucleus where it then acts as a transcription factor (Darnell 1997). Because STAT-1 function has been linked to anti-proliferative effects, we tested whether FGF treatment of RCS cells activated the STAT-1 pathway. As shown in Figure $1, \mathrm{c}$ and $\mathrm{d}$, a significant increase in STAT-1 phosphorylation, as well as increased nuclear translocation of this factor, was observed following FGF treatment. FGF treatment had no effect on STAT-3 phosphorylation and 

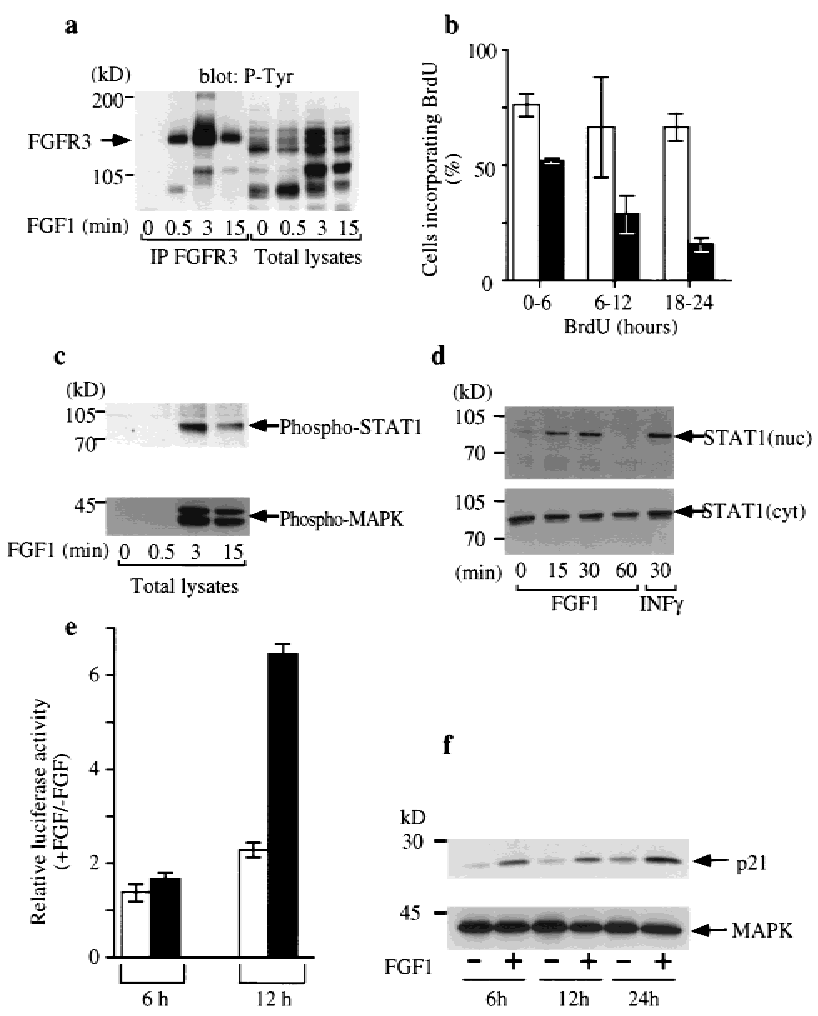

Figure 1. Activation of FGFR3 phosphorylates STAT-1 and inhibits RCS proliferation. (a) Immunoprecipitation of FGFR3 (IP FGFR3) from RCS cells untreated (0) or treated with $100 \mathrm{ng} / \mathrm{ml}$ FGF1 $(0.5,3,15 \mathrm{~min})$ followed by Western blotting with phosphotyrosine antibody 4G10. (b) RCS cells were incubated in the presence $(\square)$ or absence $(\square)$ of FGF1 (10 ng/ml) and labeled with BrdU for the times indicated after FGF addition. Each histogram represents the average of three experiments; error bars represent S.D.. (c) RCS cells were stimulated with FGF1 (100 ng/ml) and phosphorylation of STAT-1 ( $\alpha$-phospho-STAT-1, top) and MAPK ( $\alpha$-phospho-MAP kinase, bottom) was determined by Western blotting. (d) Translocation of STAT-1 to the nucleus of RCS cells following FGF stimulation. Cells were treated with FGF1 $(100 \mathrm{ng} / \mathrm{ml})$ for the times indicated and fractionated into nuclear and cytoplasmic fractions, which were subjected to SDS-PAGE and Western blotted with anti-STAT-1 antibodies. INF $\gamma$ was used as control for STAT-1 nuclear translocation (top). (e) Expression of an IRF promoter-driven plasmid is upregulated by FGF in RCS cells. Cells were transfected with 0.4 $\mu \mathrm{g} / 10^{6}$ cells of a plasmid expressing the luciferase gene under the control of the tk promoter and four copies of the STAT-1 binding sequences derived from the IRF-1 promoter ( $\mathbf{\square})$ or with the same plasmid lacking the IRF-1-derived elements ( $\square)$. The histograms represent the ratio of luciferase activity between cells treated with FGF1 $(10 \mathrm{ng} / \mathrm{ml})$ and untreated cells. FGF was added for the indicated times after washing of the calciumphosphate/DNA precipitate. (f) Protein levels of p21 WAF1/CIP1 protein increase upon treatment with $10 \mathrm{ng} / \mathrm{ml} \mathrm{FGF1} \mathrm{for} \mathrm{6,} \mathrm{12,}$ and $24 \mathrm{hr}$ (top). Western blotting of the same cell lysates with $\alpha$ ERK2 antibody (bottom) was used as a control for the amount of protein loading.

nuclear translocation (data not shown). The activation of STAT-1 in chondrocytes could lead to the induction of expression of STAT-1 target genes such as IRF1 and p21 WAF/CIP1, which are involved in inhibition of cell growth (Abdollahi et al. 1991; Chin et al. 1996). We therefore studied the effect of FGF1 treatment of RCS cells on the activity of a transiently transfected tk promoter-luciferase reporter construct containing four copies of STAT binding sites derived from the IRF1 gene. Treatment with FGF1 results in sevenfold induction of luciferase activity within the first $12 \mathrm{hr}$ (Fig. 1e). In addition, analysis of the levels of expression of p21 by Western blotting shows that FGF1 treatment results in an increase in p21 expression, while the levels of MAPK remained unchanged (Fig. 1f). The p21 increase upon FGF-1 treatment correlates well with inhibition of cell proliferation, in agreement with previous reports (Chin et al. 1996) showing that activation of STAT-1 leads to increase in p21 expression and to growth arrest in nonchondrocytic cell lines. Taken together, our results indicate that activation of FGFR3 and possibly STAT-1 activation mediate the inhibitory effect of FGF on chondrocyte proliferation in vitro.

It has been reported that signaling through F6FR1 cannot induce STAT-1 activation (Silvennoinen et al. 1993). Thus, we considered it possible that STAT-1 activation with its consequent inhibition of proliferation is specific to FGFR3. To address this question, we used NIH-3T3 cells, which express FGFR1 and FGFR2, either untransfected or stably transfected with the FGFR3 ACH mutant (NIH-3T3 ACH). FGF1 has a proliferative effect on these cells (Li et al. 1997; data not shown). Immunoprecipitation of FGFR3 from RCS and NIH-3T3 ACH cells shows that the level of expression of FGFR3 is similar in both cell types (Fig. 2a). As expected, no FGFR3 could be immunoprecipitated from untransfected NIH-3T3 cells. Autophosphorylation of FGFR3 is partially constitutive but can be increased further by ligand in NIH-3T3 ACH, whereas in RCS autophosphorylation occurs only in the presence of the ligand (Fig. 2a). Although the level of phosphorylation of FGFR3 is similar in RCS and NIH3T3 ACH cells, the extent of phosphorylation of STAT-1 is quite different (Fig. 2b). In untransfected NIH-3T3 cells that do not express FGFR3, there is weak phosphorylation of immunoprecipitated STAT-1 following FGF1 addition, possibly because of the activation of FGFR1 and/or FGFR2. This weak degree of activation is not enhanced in NIH-3T3 ACH cells (Fig. 2b). Similar results were obtained with NIH-3T3 cells expressing wild-type FGFR3 (not shown). On the other hand, STAT-1 was phosphorylated much more strongly in RCS cells than in untransfected NIH-3T3 or NIH-3T3 cells expressing FGFR3 (Fig. 2b). Thus, the introduction of FGFR3 in NIH-3T3 fibroblasts does not lead to a significant increase in FGF-induced STAT-1 activation. This suggests that rather than FGFR3 being an inhibitory receptor, the specific cell environment of chondrocytes favors STAT-1 activation and growth inhibition. A conclusive demonstration of this point will, however, require further research.

To determine whether STAT-1 activation was directly related to the inhibitory effects of FGFs on chondrocyte proliferation, we studied primary growth plate chondrocytes isolated from 10-day-old wild-type and STAT-1 
a

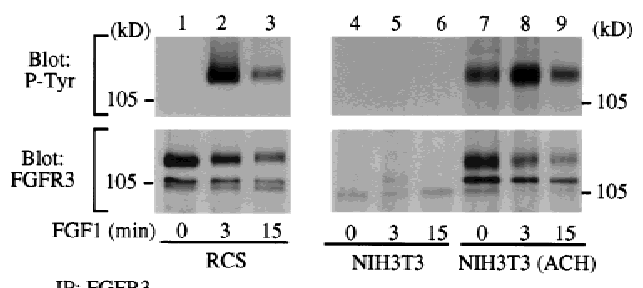

IP: FGFR3

b

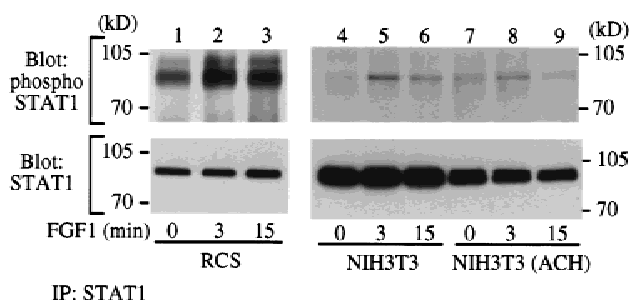

Figure 2. FGF treatment increases STAT-1 phosphorylation in RCS cells but not in NIH-3T3 ACH cells. (a) Immunoprecipitation of FGFR3 (IP FGFR3) from RCS (lanes 1-3), NIH-3T3 (lanes 4-6), and NIH-3T3 the FGFR3 ACH mutation (lanes 7-9). The immunoprecipitates were run by SDS-PAGE and Western blotted with antibodies against phosphotyrosine (P-Tyr) (top) or FGFR3 (bottom) to determine FGFR3 expression and phosphorylation. (b) Immunoprecipitation of endogenous STAT-1 from RCS (lanes 1-3), NIH-3T3 (lanes 4-6), and NIH-3T3 ACH (lanes 7-9) cells followed by SDS-PAGE and Western blotting with antibodies specific for phosphorylated STAT-1 (top) or STAT-1 (bottom). Phosphorylation of STAT-1 in FGF-treated NIH-3T3 and in NIH-3T3 ACH cells is much weaker than in RCS cells, particularly when the total amount of STAT-1 present in the cell extracts (bottom) is considered.

knockout (-/-) mice (Durbin et al. 1996). These cells express both FGFR1 and FGFR3 (Fig. 3a). Primary chondrocytes were treated with FGF1 and the rate of DNA
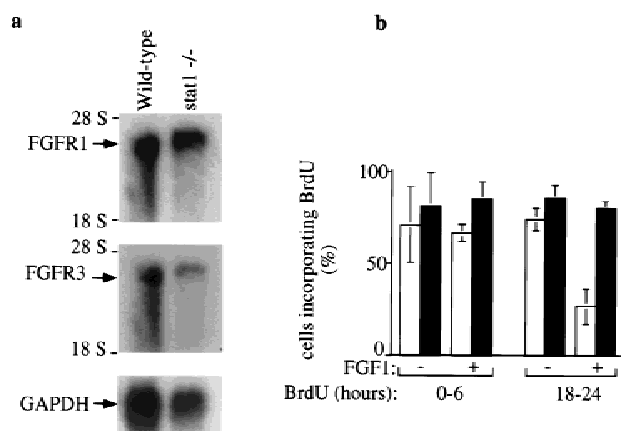

Figure 3. FGF inhibits proliferation of wild-type but not of STAT-1 knockout primary chondrocytes. (a) Northern blot analysis of FGFR1 and FGFR3 expression in wild-type and STAT-1 knockout (-/-) chondrocytes. (b) Wild-type (open bars) and STAT-1 ${ }^{-1-}$ (solid bars) growth plate chondrocytes were treated with FGF1 $(10 \mathrm{ng} / \mathrm{ml})$ and labeled with BrdU for $6 \mathrm{hr}$ at the times indicated after addition of FGF1. The frequency of Alcian blue-positive cells incorporating BrdU is shown. Each histogram represents the average of three experiments; error bars represent S.D.. synthesis measured by the frequency of cells incorporating BrdU. Double staining with Alcian blue, a marker for chondrocytic cells, allowed us to distinguish chondrocytes from nonchondrocytic cells such as fibroblasts and osteoblasts. FGF1 treatment of wild-type chondrocyte resulted in a significant decrease in chondrocyte DNA synthesis within $24 \mathrm{hr}$ (Fig. 3b). In contrast, contaminating cells such as fibroblasts, which typically represent $\sim 15 \%$ of cultures, responded to FGF treatment by an increase in their proliferation rate (data not shown). DNA synthesis in STAT-1 knockout chondrocytes was unaffected by FGF treatment, although these cells express the same FGFRs as wild-type cells (Fig. 3).

These results therefore indicate that FGF treatment of primary chondrocytes results in inhibition of cell proliferation as observed in RCS cells and that STAT-1 function is required to produce the observed growth inhibitory effect. To further confirm the involvement of STAT-1 in chondrocyte proliferation, we performed organ culture of metatarsal cartilage rudiments from E15 wild-type and STAT-1 ${ }^{-1-}$ mouse embryos. When FGF1 was added to the metatarsals, only wild-type chondrocytes exhibited a dramatic decrease in DNA synthesis, whereas the chondrocytes from STAT-1-1- showed a similar rate of DNA synthesis in the absence or presence of FGF1 (Fig. 4). Furthermore, we show that long-term treatment ( 7 days) of E15 metatarsals from wild-type embryos with FGF1 leads to a dramatic perturbance of their

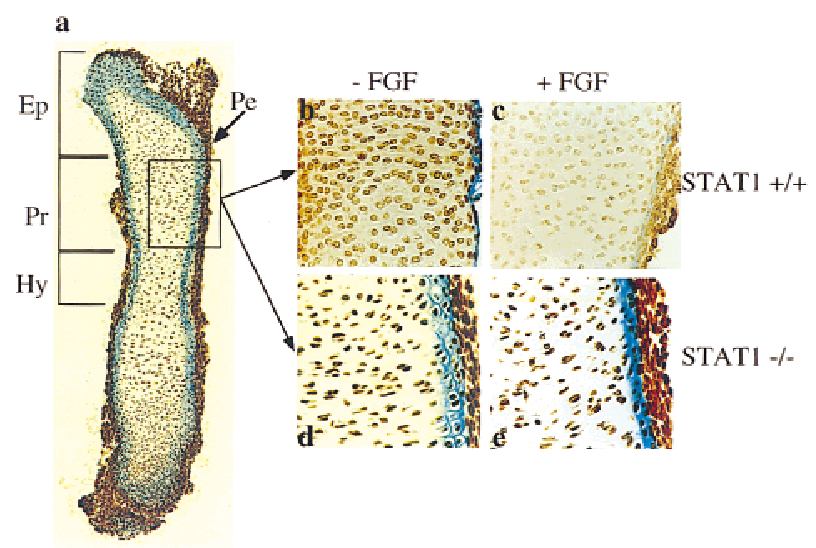

Figure 4. FGF inhibits chondrocyte proliferation in the epiphyseal growth plates of metatarsal bone rudiments from wildtype $\left(\mathrm{STAT} \mathrm{1}^{+/+}\right)$but not from STAT-1 ${ }^{-/-}$mouse embryos. (a) Longitudinal section of E15 metatarsal bone rudiments after 2 days of organ culture: (Pe) Perichondrium; (Ep) epiphyseal region; (Pr) proliferative zone; (Hy) hypertrophic zone. Detailed areas of the proliferative zone stained with anti-BrdU antibody: $(b, c)$ STAT $-1^{+/+} ;(d, e)$ STAT- $1^{-/-}$. $(b, d)$ Untreated; $(c, e)$ treated metatarsals with $200 \mathrm{ng} / \mathrm{ml}$ FGF1. FGF was present in the culture for 2 days, and BrdU was added for the last $6 \mathrm{hr}$ of culture. Cells that incorporated BrdU were visualized as described in the text. The frequency of cells incorporating BrdU was determined by counting a total of 1000 cells in three random equal areas in the proliferative zone of three independent bone sections. In untreated STAT $-1^{+/+}$metatarsals the frequency was $76 \%$, and in FGF-treated metatarsals, $24.7 \%$. In STAT- $1^{-1-}$ metatarsals $90 \%$ of the cells had incorporated BrdU without FGF treatment, and $88 \%$ with FGF treatment. 
development (Fig. 5). When E15 wild-type metatarsals, which are composed primarily of undifferentiated chondrocytes, are cultured for 7 days they undergo considerable longitudinal growth and development. They show a well-organized growth plate composed of orderly columns of proliferating chondrocytes that have undergone differentiation to prehypertrophic and hypertrophic cells positive for type $\mathrm{X}$ collagen ( $\mathrm{Col} \mathrm{X})$, a specific marker for hypertrophic chondrocytes (Fig. 5b). In contrast to the control metatarsals, the treatment of E15 cartilage rudiments with FGF1 for 7 days results in the formation of bones that are shorter and wider in their proximal and distal extremities (Fig. 5c). These metatarsals exhibit no organization of the growth plate, an absence of columnar chondrocytes, and a considerable reduction of the hypertrophic zone, as shown by staining for Col X. This demonstrates that in addition to inhibiting proliferation, FGF affects the process of the differentiation of chondrocytes.

To verify whether STAT-1 also mediates the effect of FGF signaling on bone development, we cultured E15 metatarsals from STAT-1 $1^{-/-}$embryos for the same length of time. In contrast to wild-type metatarsals, FGF treat-

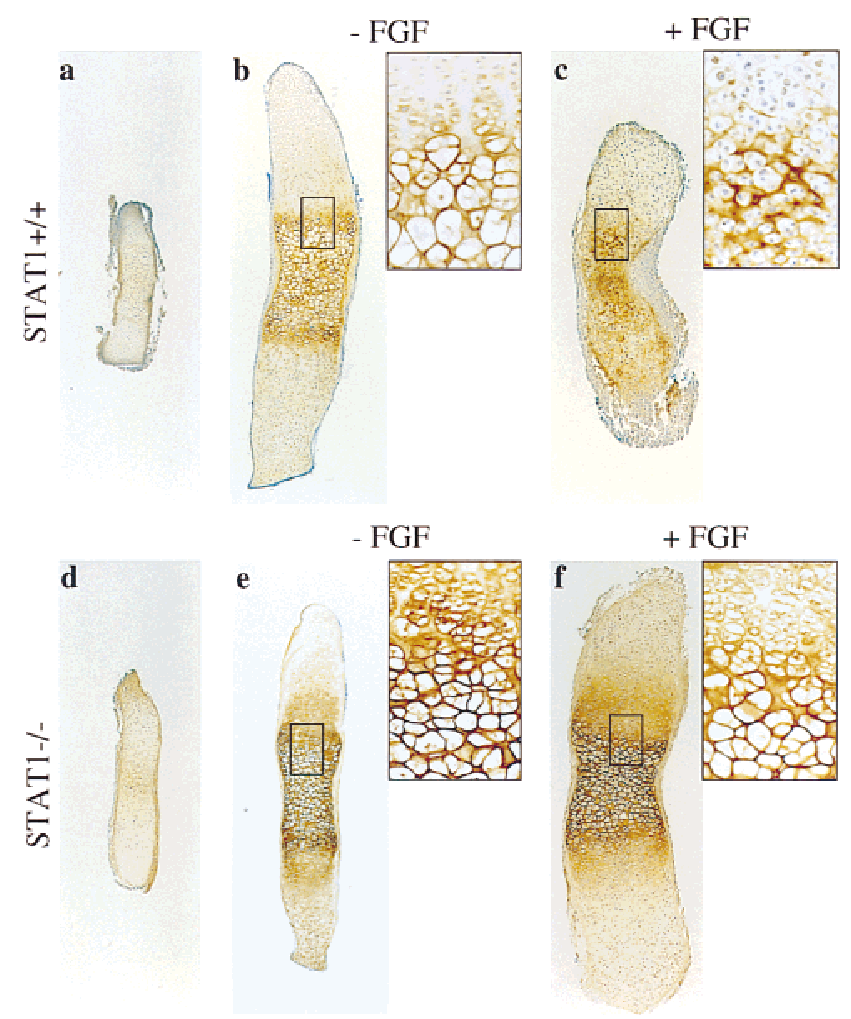

Figure 5. Long-term treatment of metatarsal rudiments by FGF causes inhibition of longitudinal growth and disruption of the growth plate in wild-type but not STAT-1 ${ }^{-/-}$rudiments. E15 metatarsals from STAT $-1^{+/+}$and STAT $-1^{-/-}$mice were cultured for 7 days in the presence or absence of $200 \mathrm{ng} / \mathrm{ml} \mathrm{FGF1.} \mathrm{Lon-}$ gitudinal sections of E.15 $(a, d)$ and 7-day cultured metatarsals $(b, c, e, f)$ were stained with a specific antibody against Col X. $(a-f)$ Micrographs have the same magnification. (Insets) A higher power view of the areas boxed in the low power adjacent micrographs, corresponding to the growth plate area. ment had no effect on growth plate chondrocytes. In both untreated and treated metatarsals, chondrocytes underwent proliferation, prehypertrophy, and terminal differentiation to hypertrophic cells that expressed Col X (Fig. 5e,f). However, FGF-treated STAT-1 $1^{-/-}$metatarsals exhibited some increase in length and width compared to controls, which could be due to the unmasking of the growth stimulatory effects of FGF signaling when the STAT-1-mediated growth inhibitory pathway is blocked. Thus, treatment with FGF of E15 bone rudiments appears to mimic the inhibition of endochondral ossification and bone development observed in human fetuses with homozygous $\mathrm{ACH}$ or TD and in mouse models (Shah et al. 1973; Stanescu et al. 1990; Naski et al. 1998; Li et al. 1999). We show that this effect also requires STAT-1 function.

It is interesting to note that in these long-term experiments, FGF treatment had no significant inhibitory effect on cells of the osteoblastic lineage and, rather, seemed to increase their proliferation. This is quite evident in the FGF-treated metatarsals shown in Figure 5c, which display a dramatic thickening of the periosteum. This phenomenon was not observed in STAT-1-1- metatarsals (Fig. 5f), suggesting either that the increased osteoblast proliferation is mediated by STAT-1 or, more likely, this effect is at least partially indirect and may require inhibition of formation of the hypertrophic zone.

The data presented in this report show that activation of FGF signaling in primary chondrocytes, chondrocytic cell lines, and cartilage bone rudiments from murine embryos results in significant inhibition of cell proliferation and bone development. This result is in line with the effect of activating FGFR3 mutations in several forms of human dwarfism, particularly $\mathrm{ACH}$ and TD, but contrasts with previous reports (Kato and Iwamoto 1990; Hill et al. 1991; Wroblewski and Edwall-Arvidsson 1995; Legeai-Mallet et al. 1998) indicating that FGF treatment of primary chondrocytes led to stimulation of cell proliferation. This discrepancy could be due to the heterogeneous nature of the cell cultures studied. A recent report (Mancilla et al. 1998) showed that FGF2 treatment of rat E20 metatarsal rudiments resulted in inhibition of DNA synthesis of proliferative and epiphyseal chondrocytes. Furthermore, we show that FGF-mediated inhibition of proliferation in chondrocytes requires STAT-1 function and that the STAT-1 requirement may be related to its ability to induce antiproliferative genes, such as $p 21^{W A F / C I P 1}$. Studies of signal transduction in a variety of cell systems have shown that although many signal transduction pathways are activated simultaneously by receptor stimulation, it has been difficult to link a specific downstream target with a specific biological response. Thus, this report presents one of the few examples in which a signal transduction pathway, STAT-1 activation, has been shown to be required for a specific cellular response, inhibition of chondrocyte proliferation. The mechanism of STAT-1 activation by FGFR3 is currently being investigated. Our data suggest that the ability to activate STAT-1 depends on the cellular context in which FGFR3 is expressed, as the introduction of 
FGFR3 or of its activating ACH mutation in fibroblasts did not lead to growth inhibition or increased ability to activate STAT-1 in response to FGF. It is interesting to note that STAT-1 $1^{-1-}$ mice have not been reported to have bone defects, but this aspect has never been studied in detail, particularly during embryonic development or during early life, and is currently under investigation. These and related studies on how FGF affects the differentiation program of cells of the chondrocytic lineage should provide important information on the mechanisms of bone morphogenesis and on the way by which unregulated FGF signaling causes bone morphogenetic disorders.

\section{Materials and methods}

Cell culture and proliferation assay

RCS cells were maintained as monolayer cultures under conditions described previously (Mukhopadhyay et al. 1995). Primary chondrocytes were isolated from long bone cartilages of 10-day-old wild-type and STAT-1 $1^{-/}$mice. Growth plates were dissected and the chondrocytes isolated as described previously (Amling et al. 1997). The growth plates were incubated with $0.1 \%$ collagenase type A (Sigma) for $30 \mathrm{~min}$ at room temperature with constant shaking. Thereafter, the supernatant was discarded, a fresh solution of $0.2 \%$ collagenase was added, and the incubation was carried out for $3 \mathrm{hr}$ at $37^{\circ} \mathrm{C}$. Cells were filtered through a sterile nylon $0.45-\mu \mathrm{m}$ mesh, centrifuged for $10 \mathrm{~min}$ at $1000 \mathrm{rpm}$. Then cells were incubated at $37^{\circ} \mathrm{C}$, in DMEM/F12 (1:1) medium supplemented with $10 \%$ FCS, $50 \mu \mathrm{g} / \mathrm{ml}$ ascorbic acid (Sigma), and $100 \mu \mathrm{g} / \mathrm{ml}$ sodium pyruvate. For proliferation assays, $5 \times 10^{4}$ cells $/ 400 \mu$ l were seeded on coverslips; for RNA extraction, $8 \times 10^{5}$ cells $/ 3 \mathrm{ml}$ were cultured in a $6-\mathrm{cm}$ tissue culture dish. The medium was changed every other day and FGF treatment was started at day 4 of the culture. For DNA synthesis, RCS cells and primary chondrocytes were incubated in the presence of $1 \mu \mathrm{g} /$ $\mathrm{ml} \mathrm{BrdU}$ for $6 \mathrm{hr}$. Cells were fixed, permealized, and incubated with anti-BrdU antibody according to the manufacturer's instructions (Boehringer Mannheim). Cells incorporating BrdU were visualized and counted using fluorescence microscopy.

\section{Organ Cultures}

Metatarsal long bone rudiments from E15 wild-type and STAT ${ }^{-/-}$mouse embryos were dissected under sterile conditions. The cartilaginous long bones were left intact. Organ culture was carried out in $\alpha$-MEM without nucleosides (GIBCO) supplemented with $50 \mu \mathrm{g} / \mathrm{ml}$ ascorbic acid, 300 $\mu \mathrm{g} / \mathrm{ml}$ L-glutamine, $50 \mu \mathrm{g} / \mathrm{ml}$ gentamicine, $250 \mu \mathrm{g} / \mathrm{ml}$ Fungizone, $1 \mathrm{~mm}$ $\beta$-glycerophosphate, and $0.2 \%$ BSA Cohn fraction V (Sigma) (complete medium). Each long bone was cultured individually in 24-well plates containing $400 \mu \mathrm{l}$ of complete medium in the presence or absence of 200 $\mathrm{ng} / \mathrm{ml}$ of recombinant human FGF1 and $10 \mu \mathrm{g} / \mathrm{ml}$ heparin. The metatarsal cultures were maintained at $37^{\circ} \mathrm{C}$ for either $48 \mathrm{hr}$ or 7 days and the medium changed every other day. The experiments were set up for left/ right paired observations, with one metatarsal serving as a control to the other. For the proliferation assay, the long bones were treated with FGF for $48 \mathrm{hr}$ and BrdU was added during the last $6 \mathrm{hr}$ of treatment. The long bones were fixed at day 0,2 , and 7 of the organ culture.

\section{Immunohistochemistry}

Metatarsals were fixed in $4 \%$ paraformaldehyde overnight at $4^{\circ} \mathrm{C}$ and embedded in paraffin, and 4 - $\mu \mathrm{m}$ tissue sections were performed. Sections were deparaffinized by treatment with xylene plus 100\%, 95\%, and $70 \%$ ethanol, followed by washes in TS buffer (100 mM Tris/ $\mathrm{HCl}$ at $\mathrm{pH} 7.4$, $150 \mathrm{~mm} \mathrm{NaCl}$ ) and permealization with $0.25 \%$ Triton X-100. For localization of Col X, sections were treated with $1 \mathrm{mg} / \mathrm{ml}$ testicular hyaluronidase at $37^{\circ} \mathrm{C}$ for $45 \mathrm{~min}$ in a humidified chamber. After overnight blocking with $3 \%$ goat serum, the endogenous peroxidase was inactivated by incubating in $5 \% \mathrm{H}_{2} \mathrm{O}_{2}$ in methanol for $10 \mathrm{~min}$. Anti-BrdU monoclonal (Boehringer Mannheim) or anti-Col X polyclonal antibody was used with a Vectastain Elite ABC Kit (Vector Labs) to stain the cells. The color reaction (dark brown) was deduced with Sigma Fast DAB peroxidase substrate according to the manufacturer's manual.
Immunoprecipitation and Western blotting

Cells were stimulated with $100 \mathrm{ng} / \mathrm{ml} \mathrm{FGF1}$ and $10 \mu \mathrm{g} / \mathrm{ml}$ heparin at $37^{\circ} \mathrm{C}$ for various times, and cells were lysed either in RIPA buffer or HNTG buffer (50 mM HEPES at pH 7.5, $150 \mathrm{~mm} \mathrm{NaCl}, 1.5 \mathrm{~mm} \mathrm{MgCl}_{2}, 1$ mM EGTA, 10\% glycerol, and 1\% Triton X-100) in the presence of protease and phosphatase inhibitors. Immunoprecipitations were performed with polyclonal anti-FGFR3 and anti-STAT-1 antibodies (Santa Cruz). Immunoprecipitates and total protein lysates were separated by SDSPAGE and analyzed by ECL detection system (Amersham). A polyclonal antibody specific for the tyrosine phosphorylated form of STAT-1 (New England Biolabs) was used in Western blot analysis when indicated.

\section{Acknowledgments}

We thank Drs. G. Inghirami and F. Gonzalez for their help in histological preparation, Dr. B.R. Olsen for providing the Col X antibody and Dr. R. Baron for the RCS cells. We thank Drs. M. Mohammadi and J. Schlessinger for providing human recombinant FGF1. This investigation was supported by a fellowship from the Arthritis Foundation to M.S. and by U.S. Public Health Service grant CA42568 from the National Cancer Institute.

The publication costs of this article were defrayed in part by payment of page charges. This article must therefore be hereby marked 'advertisement' in accordance with 18 USC section 1734 solely to indicate this fact.

\section{References}

Abdollahi, A., K.A. Lord, B. Hoffman-Liebermann, and D.A. Liebermann. 1991. Interferon regulatory factor 1 is a myeloid differentiation primary response gene induced by interleukin 6 and leukemia inhibitory factor: Role in growth inhibition. Cell Growth Differ. 2: 401-407.

Amling, M., L. Neff, S. Tanaka, D. Inoue, K. Kuida, E. Weir, W.M. Philbrick, A.E. Broadus, and R. Baron. 1997. Bcl-2 lies downstream of parathyroid hormone-related peptide in a signaling pathway that regulates chondrocyte maturation during skeletal development. I. Cell Biol. 136: 205-213.

Basilico, C. and D. Moscatelli. 1992. The FGF family of growth factors and oncogenes. Adv. Cancer Res. 59: 115-165.

Burke, D., D. Wilkes, T.L. Blundell, and S. Malcolm. 1998. Fibroblast growth factor receptors: Lessons from the genes. Trends Biochem. Sci. 23: 259-262.

Chin, Y.E., M. Kitagawa, W.-C.S. Su, Z.-H. You, Y. Iwamoto, and X.-Y. Fu. 1996. Cell growth arrest and induction of cyclin-dependent kinase inhibitor $\mathrm{p} 21^{\mathrm{WAF1} / \mathrm{CIP} 1}$ mediated by STAT1. Science 272: 719722.

Coffin, J.D., R.Z. Florkiewicz, J. Neumann, T. Mort-Hopkins, G.W. Dorn, P. Lightfoot, R. German, P.N. Howles, A. Kier, B.A. O'Toole, J. Sasse, A.M. Gonzalez, A. Baird, and T. Doetschman. 1995. Abnormal bone growth and selective translational regulation in basic fibroblast growth factor (FGF-2) transgenic mice. Mol. Biol. Cell 6: 1861-1873.

Colvin, J.S., B.A. Bohne, G.W. Harding, D.G. McEwen, and D.M. Ornitz. 1996. Skeletal overgrowth and deafness in mice lacking fibroblast growth factor receptor 3. Nat. Genet. 12: 390-397.

Darnell, J.E., Jr. 1997. STATs and gene regulation. Science 277: 16301635.

Deng, C., A. Wynshaw-Boris, F. Zhou, A. Kuo, and P. Leder. 1996. Fibroblast growth factor receptor 3 is a negative regulator of bone growth. Cell 84: 911-921.

Durbin, J.E., R. Hackenmiller, M.C. Simon, and D.E. Levy. 1996. Targeted disruption of the mouse Stat 1 gene results in compromised innate immunity to viral disease. Cell 84: 443-450.

Goldfarb, M. 1996. Functions of fibroblast growth factors in vertebrate development. Cytokine Growth Factor Rev. 7: 311-325.

Hill, D.J., A. Logan, and D. De Sousa. 1991. Stimulation of DNA and protein synthesis in epiphyseal growth plate chondrocytes by fibroblast growth factors. Interactions with other peptide growth factors. Ann. N.Y. Acad. Sci. 638: 449-452.

Kato, Y. and M. Iwamoto.. 1990. Fibroblast growth factor is an inhibitor of chondrocyte terminal differentiation. J. Biol. Chem. 265: 59035909.

Legeai-Mallet, L., C. Benoist-Lasselin, A.-L. Delezoide, A. Munnich, and J. Bonaventure. 1998. Fibroblast growth factor receptor 3 mutations 
Sahni et al.

promote apoptosis but do not alter chondrocyte proliferation in thanatophoric dysplasia. J. Biol. Chem. 273: 13007-13014.

Li, C., L. Chen, T. Iwata, M. Kitagawa, X.-Y. Fu, and C.-X. Deng. 1999. A Lys644Glu substitution in fibroblast growth factor receptor 3 (FGFR3) causes dwarfism in mice by activation of STATs and ink4 cell cycle inhibitors. Hum. Mol. Genet. 8: 35-44.

Li, Y., K. Mangasarian, A. Mansukhani, and C. Basilico. 1997. Activation of FGF receptors by mutations in the transmembrane domain. Oncogene 14: 1397-1406.

Mancilla, E.E., F. De Luca, J.A. Uyeda, F.S. Czerwiec, and J. Baron. 1998. Effects of fibroblast growth factor-2 on longitudinal bone growth. Endocrinology 139: 2900-2904.

Mukhopadhyay, K., V. Lefebvre, G. Zhou, S. Garofalo, J.H. Kimura, and B. de Crombrugghe. 1995. Use of a new rat chondrosarcoma cell line to delineate a 119-base pair chondrocyte-specific enhancer element and to define active promoter segments in the mouse Pro- $\alpha 1$ (II) collagen gene. J. Biol. Chem. 270: 27711-27719.

Naski, M.C. and D.M. Ornitz. 1998. FGF signaling in skeletal development. Front. Biosci. 3: 781-794.

Naski, M.C., J.S. Colvin, J.D. Coffin, and D.M. Ornitz. 1998. Repression of hedgehog signaling and BMP4 expression in growth plate cartilage by fibroblast growth factor receptor 3. Development 125: 4977-4988.

Ornitz, D.M., J. Xu, J.S. Colvin, D.G. McEwen, C.A. MacArthur, F. Coulier, G. Gao, and M. Goldfarb. 1996. Receptor specificity of the fibroblast growth factor family. J. Biol. Chem. 271: 15292-15297.

Saxton, T.M., M. Henkemeyer, S. Gasca, R. Shem, D.J. Rossi, F. Shalaby, G.-S. Feng, and T. Pawson. 1997. Abnormal mesoderm patterning in mouse embryos mutant for the SH2 tyrosine phosphatase Shp-2. $E M B O$ J. 16: 2352-2364.

Shah, K., R. Astley, and A.H. Cameron. 1973. Thanatophoric dwarfism. J. Med. Genet. 10: 243-252.

Silvennoinen, O., C. Schindler, J. Schlessinger, and D.E. Levy. 1993. Rasindependent signal transduction in response to growth factors and cytokines by tyrosine phosphorylation of a common transcription factor. Science 261: 1736-1739.

Stanescu, R., V. Stanescu, and P. Maroteaux. 1990. Homozygous achondroplasia: Morphologic and biochemical study of cartilage. Am. J. Med. Genet. 37: 414-421.

Su, W.-C., M. Kitagawa, N. Xue, B. Xie, S. Garofalo, J. Cho, C. Deng, W.A Horton, and X.-Y. Fu. 1997. Activation of Stat1 by mutant fibroblast growth-factor receptor in thanatophoric dysplasia type II dwarfism. Nature 386: 288-292.

Webster, M.K. and D.J. Donoghue. 1997. FGFR activation in skeletal disorders: Too much of a good thing. Trends Genet. 13: 178-182.

Wroblewski, J. and C. Edwall-Arvidsson. 1995. Inhibitory effects of basic fibroblast growth factor on chondrocyte differentiation. J. Bone Miner. Res. 10: 735-742. 


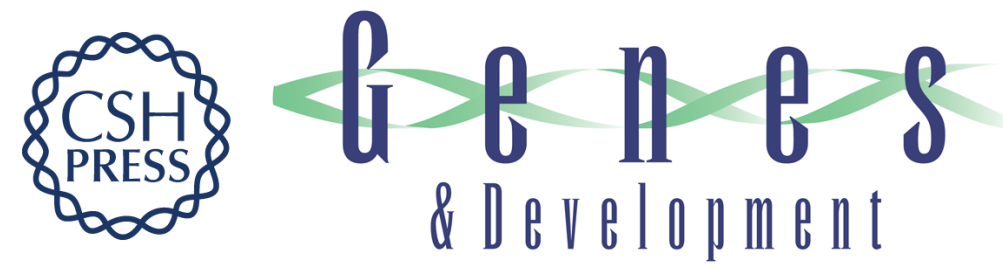

\section{FGF signaling inhibits chondrocyte proliferation and regulates bone development through the STAT-1 pathway}

Malika Sahni, Davide-Carlo Ambrosetti, Alka Mansukhani, et al.

Genes Dev. 1999, 13:

References This article cites 27 articles, 13 of which can be accessed free at:

http://genesdev.cshlp.org/content/13/11/1361.full.html\#ref-list-1

License

Email Alerting Receive free email alerts when new articles cite this article - sign up in the box at the top Service right corner of the article or click here.

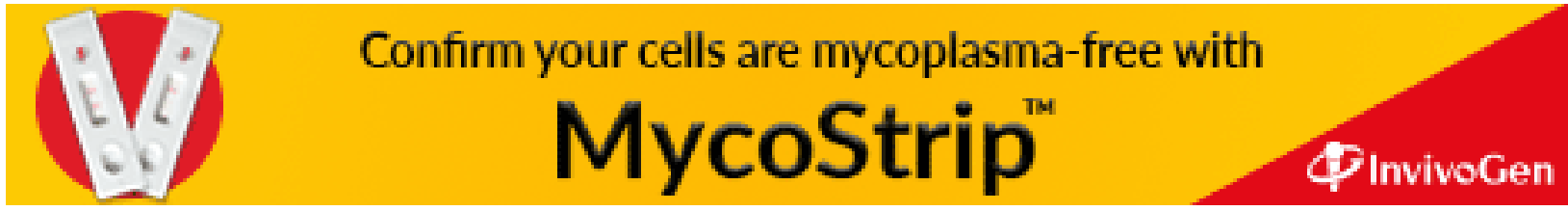

